\title{
A case of congenital insensitivity to pain with anhidrosis
}

To the Editor,

Congenital insensitivity to pain with anhidrosis (CIPA) syndrome is a rare autosomal recessive disease which is also known as hereditary sensory and autonomic neuropathy type 4 (1). The prominent characteristics of the disease include fever due to anhidrosis, absence of sense of pain, painless ulcers in the structures inside the mouth and extremities, self-harm behavior, mild to severe mental retardation, myelination defect in the sural nerve biopsy and loss of small myelinized fibers. Infection in the fingers and toes, lips and tongue and scarring is observed commonly. Keratoderma palmoplantaris is a typical finding in the advanced period $(1,2)$. Other problems include chronic bone and joint infections.

Inability to sense pain and absence of hidrosis in the patients arise from absence of sympathetic nerve supply of the afferent neurons of pain and eccrine sweat glands due to tissue damage. These neurons originate from neural crest cells and are localized in the dorsal root ganglion. The cell is stimulated by the "Nerve Growth Factor" (NGF) and TRKA receptors. TRKA is a tyrosine kinase receptor with high affinity and is activated by NGF. In patients with congenital insensitivity to pain with anhidrosis syndrome, mutations in the TRKA (NTRKl) gene which codes the TRKA receptor have been defined. Since congenital insensitivity to pain with anhidrosis syndrome is a rare disease, a child with this syndrome is presented here to draw attention to early diagnosis.

A 10 year-old male patient presented to the pediatric emergency department with fever, ulcers on the skin which did not heal and erythema on the left amputated extremity. It was learned that the complaint of fever recurred intermittently since the delivery and he was frequently hospitalized because a focus of infection could not be found, his left foot was amputated because of chronic osteomyelitis approximately one year ago, multiple ulcers occured on his feet, hands, fingers and toes, knees and elbows from the time he started to walk, some of these ulcers healed, but some healed with much difficulty and even did not heal and some fingers were lost because the ulcers did not heal, he never sweated from the time of delivery and did not feel pain when he was exposed to any trauma. He had frequent hospitalizations because of skin infection and fever, recurrent febrile convulsions and follow-up with a diagnosis of keratoderma in dermatology clinics where he was referred because of skin lesions in his personal history. He had no additional pathology in his familial history. On physical examination, his consciousness was open, he had no interest for the environment, he did not speak and there was no eye contact, he had mental retardation. His weight and height were compatible with his peers. Pulse rate: $96 / \mathrm{min}$, blood pressure: 115/70 $\mathrm{mmHg}$, fever: $39^{\circ} \mathrm{C}$, respiratory rate: $28 / \mathrm{min}$, oxygen saturation: $99 \%$. Oral hygiene was poor, varying degrees of eruptions were present in the tooth, cracked and eroded lesions were present in the tongue and lips and tissue loss was present in the distal parts of the fingers (Figure 1). Eroded and ulcerated lesions were present between various fingers and toes from place to place. Hyperkeratotic swollen lesions with irregular surface were observed especially around the knees and elbows. The left lower extremity was amputated in the middle of the tibia and there was erythema, induration and increased warmth on the amputation area (Figure 2). There was an sharply circumscribed ulcerated lesion with dimensions of $2 \times 3 \mathrm{~cm}$ on an erythematous background sunken from the surface (Figure 3). Cranial nerve examination and muscle strength were found to be normal. Muscle tonus was mildly reduced. Deep tendon reflexes were normoactive. He was insensitive against deep and superficial pain stimuli. No marked pathology was found on the examination of the other systems. Laboratory findings were as follows: WBC $16800 / \mathrm{mm}^{3}$, absolute neutrophil count $10300 / \mathrm{mm}^{3}$, absolute lymphocyte count $4400 / \mathrm{mm}^{3}$, $\mathrm{Hb}$ $9.5 \mathrm{~g} / \mathrm{dL}, \mathrm{MCV} 77.9 \mathrm{fL} / \mathrm{mm}^{3}$, RDW 15.9\%, platalet count 362 000/ $\mathrm{mm}^{3}$, erythrocyte sedimentation rate $77 \mathrm{~mm} / \mathrm{h}, \mathrm{C}-\mathrm{reactive}$

Address for Correspondence: Ahmet Kağan Özkaya, Department of Pediatrics, Kahramanmaraş Sütçü İmam University Faculty of Medicine, Kahramanmaraş, Turkey. E-mail: kaganozkaya@yahoo.com

Received: 19.08.2013 Accepted: 10.12.2013

(C) Copyright 2014 by Turkish Pediatric Association - Available online at www.turkpediatriarsivi.com

DOI:10.5152/tpa.2014.1549 


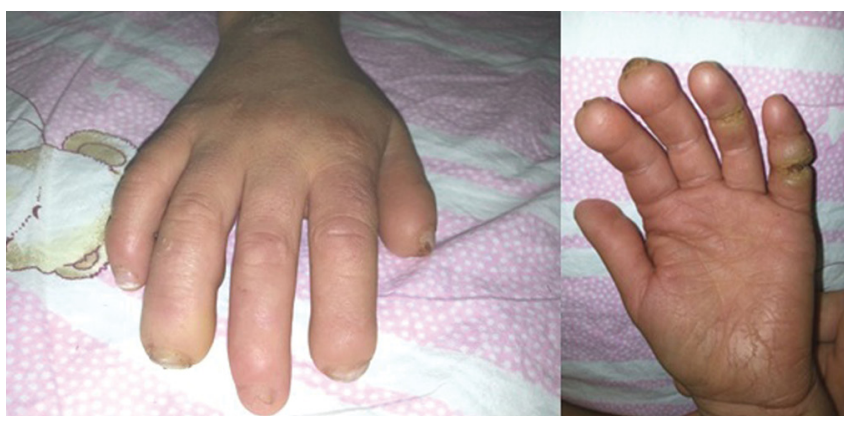

Figure 1. Tissue loss and deformations in the distal parts of the fingers, contracture and unhealing wounds in the fingers

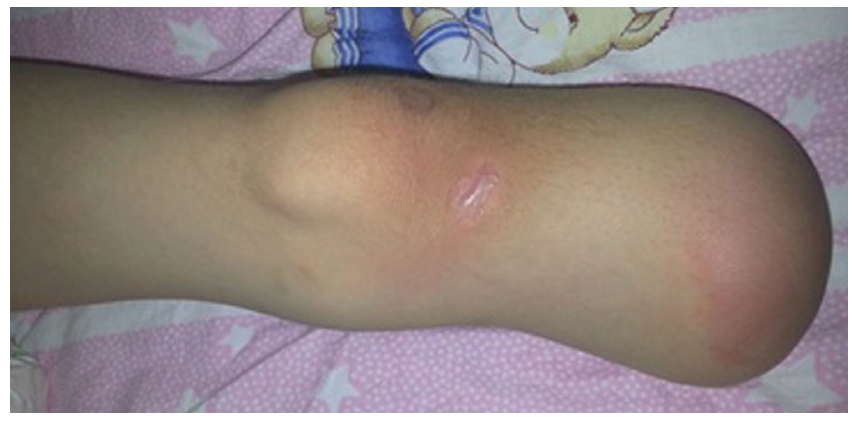

Figure 2. Hyperemia in the skin in the distal part of the left amputated lower exremity

protein $97.3 \mathrm{mg} / \mathrm{dL}$, blood glucose $87 \mathrm{mg} / \mathrm{dL}$, BUN $8 \mathrm{mg} / \mathrm{dL}$, creatinine $0.3 \mathrm{mg} / \mathrm{dL}$, uric acid $2.2 \mathrm{mg} / \mathrm{dL}$, creatinine kinase $55 \mathrm{U} / \mathrm{L}$. Serum electrolytes were within the normal limits. Chormosome analysis of the patient was found to be $46 \mathrm{XY}$. Electromyography, cranial magnetic resonance imaging, serum vitamin B12, folic acid, zinc levels were found to be normal. Serum immunoglobulins were compatible with the age. The pilocarpin iontophoresis test was found to be negative. He had moderate mental retardation according to the "Wechsler Intelligence Scale for Children". The patient was hospitalized in the ward because of congenital insensitivity to pain and soft tissue infection. Antibiotic treatment was started after obtaining samples for blood culture and wound site culture.

Pain is a warning, preventive or therapeutic, protective function against damage. When a patient with congenital insensitivity to pain with anhidrosis seriously injures himself/ herself, injury is generally not recognized and permanent wounds occur as a result. Hydrosis is an important function to keep the body temperature within normal limits in warm environments. Anhidrosis leads to recurrent febrile convulsions due to disruption in maintanence of the body temperature and hyperthermia. In patients with congenital insensitivity to pain with anhidrosis syndrome, absense of sense of pain and heat is related with absence of nerve supply of the fibers which conduct the sense of pain and of the eccrine sweat glands (3). Insensitivity to pain and anhidrosis were prominent characteristics in our patient.

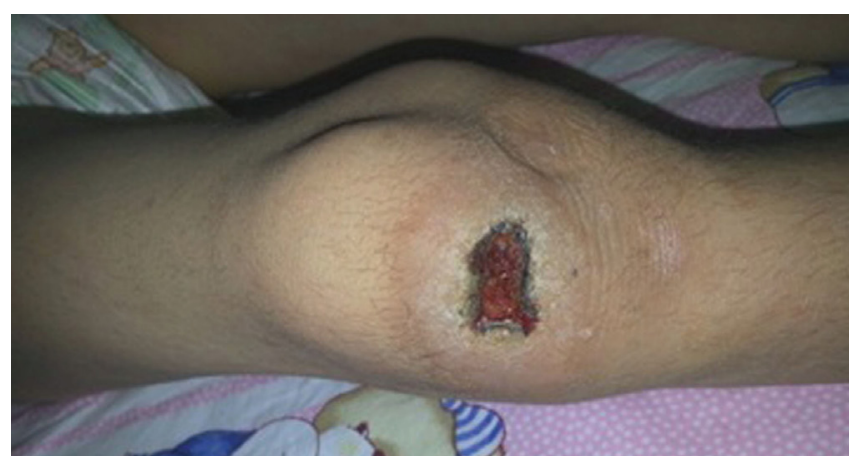

Figure 3. Ulcerated necrotic lesion in the periphery on the right patella which has not healed for a long time

In patients with congenital insensitivity to pain with anhidrosis, oral lesions, tissue loss in the fingers, tongue and lips, wound site infection, acute and chronic osteomyelitis, finger amputations and joint abnormalities are frequently found because of self harm behavior (1). In these patients, the pilocarpin iontophoresis test is negative. In the literature, nerve supply of the eccrine sweat glands have been found histopathologically in some patients despite a negative pilocarpine iontophoresis test (2). However, Sztriha et al. (1) showed that the present nerve fiber were dysfunctional with immunohistochemical staining methods. Our patient had a clinical history of anhidrosis and the pilocarpin iontophoresis test was found to be negative.

Findings including hypotonia, absence of deep tendon reflexes or decreased deep tendon reflexes are expected in patients with congenital insensitivity to pain with anhidrosis (1). Loss of muscle fibers, variability in their size, appearance of a central nucleus, endomisial fibrosis and presence of vacuolar formation are known in patients with CIPA. It is thought that changes in muscle and deep tendon reflexes are related with chronic neuropathic and myopathic changes $(4,5)$.

In patients with congenital insensitivity to pain with anhidrosis, mental retardation is observed frequently. Although microcephaly is an expected finding, enlargement in the ventricles and hydrocephaly have been found in some patients (6). Our patient had mental retardation, but magnetic resonance imaging findings were found to be normal.

When the nerve growth factor (NGF)-TRKA system does not function fully, the nerve fibers which are related with the sense of pain and which provide specific nerve supply to the eccrine sweat glands are absent in the organism or do not function (3). It is known that the nerve growth factor has a regulatory role in neuroimmune and endocrine interaction and it has been found in periosteal osteoprogenitor cells. Changes in the functions of these cells may be a facilitating factor in skeletal involvement in patients with CIPA. Many and varying types of mutations have been found in the TRKA gene. The disease is most probably inherited with autosomal dominant inheritance, but it has also been shown to be inher- 
ited by "unipaternal" disomy $(1,3)$. Thus, this should be kept in mind when giving genetic counseling service to patients with CIPA.

Informed Consent: Written informed consent was obtained from the parents of patient who participated in this study.

Peer-review: Externally peer-reviewed.

Author Contributions: Concept - A.K.Ö., E.G.; Design - A.K.Ö., E.G., A.R.N., O. G.; Supervision - A.K.Ö., E.G.; Funding - A.K.Ö., O.G.; Materials - A.K.Ö., E.A., A.R.N.; Data Collection and/or Processing - A.K.Ö., E.G., E.A., A.R.N., D.C., O.G.; Analysis and/ or Interpretation - A.K.Ö., E.G., E.A., A.R.N., D.C., O. G.; Literature Review - A.K.Ö., E.G.; Writer - A.K.Ö., E.G.; Critical Review - E.G., O.A.; Other - D.C.

Conflict of Interest: No conflict of interest was declared by the authors.

Financial Disclosure: The authors declared that this study received no financial support.
Ahmet Kağan Özkaya, Ekrem Güler, Elif Arık, Ali Rıza Namlı, Derya Cevizli, Olcay Güngör

Department of Pediatrics, Kahramanmaraş Sütçü İmam University Faculty of Medicine, Kahramanmaraş, Turkey

\section{References}

1. Sztriha L, Lestringant GG, Hertecant J, et al. Congenital insensitivity to pain with anhidrosis. Pediatr Neurol 2001; 25: 63-6. [CrossRef]

2. Berkovitch M, Copeliovitch L, Tauber T, et al. Hereditary insensitivity to pain with anhidrosis. Pediatr Neurol 1998; 19: 227-9. [CrossRef]

3. Indo Y. Molecular basis of congenital insensitivity to pain with anhidrosis (CIPA): mutations and polymorphisms in TRKA (NTRKl) gene encoding the receptor tyrosine kinase for nerve growth factor. Hum Mutat 2001; 18: 462-71. [CrossRef]

4. Shorer Z, Shaco-Levy R, Pinsk V, et al. Variation of muscular structure in congenital insensitivity to pain and anhidrosis. Pediatr Neurol 2013; 48: 311-3. [CrossRef]

5. Tachi N, Ohya K, Chiba S, et al. Muscle involvement in congenital insensitivity to pain with anhidrosis. Pediatr Neurol 1995; 12: 264-6. [CrossRef]

6. Vasella F. Congenital sensory neuropathy with anhidrosis. Arch Dis Child 1968; 43: 124-30. [CrossRef] 